\title{
ERRATUM
}

Open Access

\section{Erratum to: Mechanical properties of High and Very High Steel at elevated temperatures and after cooling down}

Chrysanthos Maraveas $^{1 *}$, Zacharias C. Fasoulakis ${ }^{2}$ and Konstantinos Daniel Tsavdaridis ${ }^{3}$

\section{Erratum}

Upon publication of the original article (Maraveas et al., 2017), it was noticed that the article title was captured incorrectly. The correct title of the paper is: "Mechanical Properties of High and Very High Strength Steel at Elevated Temperatures and after cooling down".

\footnotetext{
Author details

${ }^{1}$ University of Liege, Liege, Belgium. ${ }^{2}$ National Technical University of Athens,

Athens, Greece. ${ }^{3}$ University of Leeds, Leeds, UK.
}

Received: 29 July 2017 Accepted: 2 August 2017

Published online: 09 August 2017

\section{Reference}

Maraveas C, Fasoulakis ZC, Tsavdaridis KD (2017) Mechanical properties of High and Very High Steel at elevated temperatures and after cooling down. Fire Science Reviews 6:3. doi:10.1186/s40038-017-0017-6

\footnotetext{
* Correspondence: c.maraveas@maraveas.gr

'University of Liege, Liege, Belgium
} 